\title{
Potentiometric Biosensors: Concept and Analytical Applications-An Editorial
}

\section{Aurelia Magdalena Pisoschi* \\ Faculty of Veterinary Medicine, University of Agronomic Sciences and Veterinary Medicine of Bucharest, Bucharest, Romania}

*Corresponding author: Aurelia Magdalena Pisoschi, Faculty of Veterinary Medicine, University of Agronomic Sciences and Veterinary Medicine of Bucharest, Bucharest, Romania, Tel: +40 21318 2266; E-mail: aureliamagdalenapisoschi@yahoo.ro

Rec date: Jul 29, 2016; Acc date: Jul 31, 2016; Pub date: August 3, 2016

Copyright: (C) 2016 Pisoschi AM, This is an open-access article distributed under the terms of the Creative Commons Attribution License, which permits unrestricted use, distribution, and reproduction in any medium, provided the original author and source are credited.

\section{Editorial}

Potentiometric assays rely on recording the potential $/ \mathrm{pH}$ variation, and these determinations are applicable in food, clinical or environmental analysis. The analytical signal is due to the concentration variation of an ionic species.

Potentiometric measurements are applied to the determination of many organic and inorganic species (sugars, urea, antibiotics, neurotransmitters, pesticides, but also ammonia, carbon dioxide and many ionic species).

Potentiometric biosensors are developed by combining a biorecognition element (essentially an enzyme) with a transducer that senses the variation in protons (or other ions) amount, the recorded analytical signal being logarithmically correlated with the analyte concentration.

The present Editorial deals with the presentation of several types of sensors based on different transducers and biorecognition elements.

The simplest transducer in the development of potentiometric biosensors is the glass $\mathrm{pH}$ electrode. Glucose oxidase immobilization was achieved using cellophane [1], nylon [1-6] or nitrocellulose [5,7] membranes that are subsequently fixed on the sensitive bulb of the $\mathrm{pH}$ electrode that senses the $\mathrm{pH}$ diminution, as a result of the biocatalytical reaction occurring in the enzyme layer (glucose oxidation by glucose oxidase). Such potentiometric enzyme sensors possess a linear range of $10^{-4}$ to $5 \times 10^{-2} \mathrm{M}$, allowing for glucose assay in fruit juices [4].

Glucose oxidase has been also coupled with other signal transducers for potentiometric purposes: the enzyme has been entrapped in a polypyrrole film by electro-polymerization on a Pt electrode, resulting in a potentiometric glucose biosensor [8].

Ion selective electrodes other than the $\mathrm{pH}$ glass electrode, such as the fluoride electrode, were also used in the development of potentiometric sensors. Glucose, maltose or lactate can be determined relying on the reaction of 4-fluoroaniline with $\mathrm{H}_{2} \mathrm{O}_{2}$ generated by the corresponding substrate oxidases. The fluoride anions resulted from the peroxidase-catalyzed reaction of fluoroaniline with hydrogen peroxide that involves cleavage of the C-F bond, are potentiometrically detected with the specific fluoride electrode. The analytical signal represented by the recorded voltage difference depends linearily on the logarithm of the analyte concentration within the range 0.1-1 mM [9].

Amygdalin can be assessed with a potentiometric biosensor using as transducer a cyanide anion selective electrode [10].

Enzymes such as glucose oxidase, lipase or acetylcholinesterase, were also immobilized on the sensitive membranes of ion-selective field effect transistors, resulting in the determination of glucose, triglycerides and pesticides respectively [11-13].

The development of potentiometric biosensors can also involve gassensitive electrodes (such as for carbon dioxide and ammonia resulted from enzyme reactions), as in the case of urea determination [14]. Gas-sensitive electrodes as transducers are obtained on the basis of a $\mathrm{pH}$ glass electrode and an electrolyte layer that is maintained close to the sensitive bulb by a gas-permeable membrane [15].

Increasingly complex electrode modification resulted in excellent analytical parameters:

Hypoxanthine assessment in fish meat was performed using a potentiometric enzyme electrode relying on xanthine oxidase and ferrocene carboxylic acid entrapment in a polypyrrole film that was obtained by applying galvanostatic technique. The linear range of analytical response of the developed enzyme sensor was 5-20 $\mu \mathrm{M}$ [16].

The immobilization of acetylcholinesterase on an antimony disk electrode by intermolecular cross-linkage of the enzyme and bovine serum albumin, using glutaraldehyde vapor, resulted in a potentiometric sensor enabling the assay of trichlorfon with fast response, given the ability of the organophosphorous pesticide to inhibit AChE [17]

A solid-state electrode consisting in a conducting resin (graphite/ epoxy) and polyvinyl chloride matrix and responding to ammonium ions was used as transducer in urea assay [18].

Another type of urea biosensor consists of a glass-sealed metal microelectrode coated with a polyethylenimine film. Physical adsorption and subsequent reticulation with diluted aqueous glutaraldehyde solution for urease immobilization, resulted in enhanced analytical performances meaning short response times (15$30 \mathrm{~s}$ ), a dynamic range with sigmoidal response versus urea for a concentration range $1 \times 10-2.5$ to $1 \times 10-1.5 \mathrm{M}$ and a lifetime of 4 weeks [19].

Urease immobilization on a modified fullerene nanomaterial and subsequent deposition on a screen-printed electrode that contained a poly (n-butyl acrylate) membrane entrapped with a hydrogen ionophore, resulted in a novel biosensor. The linearity of the biosensor was comprised between $2.31 \times 10^{-3} \mathrm{M}$ and $8.28 \times 10^{-5} \mathrm{M}$. The sensitivity of the biosensor was very close to the theoretical Nernstian slope: $59.67 \pm 0.91 \mathrm{mV} /$ decade. Tests performed on cations commonly present in urine samples such as $\mathrm{Na}+\mathrm{K}+, \mathrm{Ca}^{2+}, \mathrm{Mg}^{2+}$ and $\mathrm{NH}^{4+}$ showed that these ionic species did not interfere with the urea analytical signal. The results obtained in real urine samples range between 17 and $19 \mathrm{mM}$, the difference between the results of UV-Vis 
Citation: Pisoschi AM (2016) Potentiometric Biosensors: Concept and Analytical Applications-An Editorial. Biochem Anal Biochem 5: e164. doi:

Page 2 of 2

standard spectrometry and those obtained with the potentiometric biosensor being smaller than $5 \%[20]$.

The analytical parameters and methods' validation confirm the viability of the developed potentiometric sensors, for the assessment of various key biomolecules.

\section{References}

1. Pisoschi AM, Danet AF, Negulescu Gh P (2006) Glucose determination by cellophane-based and nylon-based enzymic electrodes; Application on juices and wine analysis. Electron J Environ Agric Food Chem 5: 1185-1194.

2. Pisoschi AM, Danet AF (2005) Influence of the buffer capacity on the response of a potentiometric Biodyne-based enzyme electrode for glucose. In Proceedings of BRAMAT 2005, Sect. 6: 7, ISBN: 973-635-454-7, Brasov, 24-26 February 2005, Brasov, Romania.

3. Pisoschi AM, Danet AF (2005) Comparison between nylon-based and cellophane-based potentiometric biosensor in glucose assessment, Application on glucose analysis in natural juices and wines. Env Edu 2005, Trends in Environmental Education. Book of Abstracts, Brasov, Romania 8-10 September 2005: 41.

4. Pisoschi AM, Danet AF (2004) Construction and determination of the analytical characteristics of a glucose potentiometric biosensor. Rev Chim 55: 843-850.

5. Pisoschi AM, Danet AF (2006) Comparison between nylon-based and nitrocellulose-based potentiometric biosensors in glucose assessment. Anal Univ Bucuresti- Chimie, year XVI: 39-44.

6. Pisoschi AM, Danet AF, Negulescu Gh P (2007) Influence of the buffer capacity on glucose potentiometric determination in synthetic solutions and in real samples with different acidities. Proc Rom Acad Series B 2: 75-81.

7. Pisoschi AM, Danet AF, Negulescu Gh P (2007) Glucose determination in synthetic solutions, juices and wine by potentiometric enzyme electrodes based on cellulose-derived semipermeable membranes. Proc Rom Acad Series B 9: 183-187.

8. Adeloju SB, Moline AN (2001) Fabrication of ultra-thin polypyrroleglucose oxidase film from supporting electrolyte-free monomer solution for potentiometric biosensing of glucose. Biosens Bioelectron 16: 133-139.
9. Dransfeld I, Hintsche R, Scheller F (1989) Enzymelektroden für Lactat und Maltose auf der Basis einer fluoridionensensitiven Elektrode. Fresenius'Z Anal Chem 333: 23-25.

10. Llenado RA, Reichnitz GA (1971) Improved enzyme electrode for amygdalin. Anal Chem 43: 1457-1461.

11. Volotovsky V, Soldatkin AP, Shulga AA (1996) Glucose-sensitive ionsensitive field-effect transistor-based biosensor with additional positively charged membrane. Dynamic range extension and reduction of buffer concentration influence on the sensor response. Anal Chim Acta 322: 77-81.

12. Kumar Reddy RR, Chadha A, Bhattacharya E (2001) Porous silicon based potentiometric triglyceride biosensor. Biosen Bioelectron 16: 313-317.

13. Ristori C, Del Carlo C, Martini M, Barbaro A, Ancarani A (1996) Potentiometric detection of pesticides in water samples. Anal Chim Acta 325: 151-160.

14. Singh M, Verma N, Garg AK, Redhu N (2008) Urea biosensors. Sensors and Actuators B 134: 345-351.

15. Pisoschi AM (2013) Biosensors as bio-based materials in chemical analysis: A Review. J Biobased Mater Bioenergy 7: 19-38.

16. Lawal AT, Adeloju SB (2012) Mediated xanthine oxidase potentiometric biosensors for hypoxanthine based on ferrocene carboxylic acid modified electrode. Food Chem 135: 2982-2987.

17. Gyurcsányi RE, Vágföldi Z, Tóth K, Nagy G (1999) Fast response potentiometric acetylcholine biosensor. Electroanalysis 11: 712-718.

18. Alegret S, Martinez-Fabregas E (1989) Biosensors based on conducting filled polymer all-solid-state PVC matrix membrane electrode. Biosensors 4: 287-297.

19. Lakard B, Herlem G, Lakard S, Antoniou A, Fahys B (2004) Urea potentiometric biosensor based on modified electrodes with urease immobilized on polyethylenimine films. Biosens Bioelectron 19: 16411647.

20. Saeedfar K, Heng LY, Ling TL, Rezayi M (2013) Potentiometric urea biosensor based on an immobilised fullerene-urease bio-conjugate. Sensors 13: $16851-16866$. 